\title{
Dynamics of redox conditions in shallow freshwater sediments as principle control on nutrient speciation and mobility
}

\author{
GREGORY DRUSCHEL ${ }^{1}$, JOHN T SHUKLE ${ }^{2}$, MARTIN R \\ KUREK $^{3}$, MOURAD HARIR ${ }^{4}$, PHILIPPE SCHMITT- \\ KOPPLIN $^{5}$ AND ANDREW SCHROTH ${ }^{6}$ \\ ${ }^{1}$ IUPUI \\ ${ }^{2}$ Indiana University - Purdue University Indianapolis \\ ${ }^{3}$ Indiana University Purdue University Indianpolis \\ ${ }^{4}$ Helmholtz Zentrum München \\ ${ }^{5}$ TUM, WZW, Institute of Analytical Food Chemistry \\ ${ }^{6}$ University of Vermont \\ Presenting Author: gdrusche@iupui.edu
}

Phosphorus (P) mobility is often tied to iron oxide mineralogy and the redox biogeochemical reactions governing their formation, dissolution, ripening, and recrystallization kinetics. Missisquoi Bay, a shallow, eutrophic bay located at the northern end of Lake Champlain has been a study site for our work the last 10 years and a series of field measurements have established the mobility of $\mathrm{P}$ forms tied to changing redox chemistry and iron oxide minerals (Smith et al., 2011; Giles et al., 2015; Schroth et al., 2015; Joung et al., 2017; Isles et al., 2017). We have followed this work up with a series of mesocosm experiments, utilizing cores from the same study site in Mississquoi Bay, collected by SCUBA diving, using glass core tubes with a nitrogen/air gas control system developed to control redox front positioning. These experiments define the timescales in which reduction progresses to drive the redox front down, dissolve iron oxides, and release $\mathrm{P}$, and the timescales in which a reduced condition at the sediment water interface can become oxidized and reverse the flux of $\mathrm{P}$ between the water column and sediment. Oscillating redox conditions between oxic and reducing at the sediment-water interface affect the overall kinetics of these reactions as well, by changing the character of the iron oxide mineral pool. Phosphorus mobility is also a function of phosphorus speciation, with organic pools of $\mathrm{P}$ additionally behaving differently under changing redox conditions. These observations and data have permitted construction of an improved conceptual and quantitative model describing nutrient cycling in shallow freshwater systems, where seasonal and diel fluctuations of redox chemistry across a critical slice of minerals, microbes, and water at the sediment-water interface control P flux and impact harmful algal blooms. 